\title{
Volatile anesthetics as a neuroprotective agent
}

\author{
Sungsik Park \\ Department of Anesthesiology and Pain Medicine, School of Medicine, Kyungpook National University, Daegu, Korea
}

Pharmacologic protection of brain from ischemic insult has been intensively investigated since the early 1960s [1] and a considerable amount of work has been performed to show the effectiveness of various drugs. Among these studies, anesthetic agents, including intravenous and volatile drugs, were shown to be promising agents.

In an article published in this issue of the Korean Journal of Anesthesiology, Park et al. [2] present the neuroprotective effect of sevoflurane on forebrain ischemic injury in a rat model. They show the protective effect of sevoflurane in near-complete brain ischemia and the influence of time on the ischemia in the rat brain.

In previous studies, the effects of anesthetic agents on ischemic insults were shown to vary depending on the ischemic intensity. Among these studies, Miura et al. [3] demonstrated that isoflurane, ketamine or nitrous oxide and fentanyl had neuroprotective effects against incomplete brain ischemic, but in near-complete global ischemic, only isoflurane was effective. In addition, Park et al. confirmed that in near-complete ischemia, sevoflurane also displayed neuroprotective properties in rats. Volatile anesthetics were shown to be neuroprotective in an acute ischemic rat model.

Park et al. performed TUNEL staining, which measures apoptosis of neurons, on the 7 th day after ischemic insult and did not observe any differences between the control and sevoflurane group. However, when using an incomplete brain ischemia model, Pape et al. [4] found that sevoflurane had long-term effects on neuronal cell damage and expression of apoptotic factors. Engelhard et al. [5] also investigated the effect of propofol on neuronal ischemia after incomplete cerebral ischemia. They found reduced neuronal cell damage and favorable modulation of apoptosis-regulating proteins over long-term period. But Bayona et al. [6] showed that propofol infusion was protective until 3 days after ischemic insult; however, after 3 weeks there were no differences compared to the control group. Kawaguchi et al. [7] concluded that isoflurane delays but does not prevent cerebral infarction in rats subjected to focal ischemia. In this regard, it seems that the long-term neuroprotective action of anesthetic agents is only effective when the ischemic insult is mild and the neuroprotective effect is not sustained for near-complete ischemic. But these shortterm effects in near-complete ischemia can still save time to allow for the use of other agents directed against apoptosis.

Park et al. also demonstrate the effect of ischemic duration on the severity of ischemia. It is reasonable to conclude that shorter duration produces less damage than longer duration.

These combined finding indicate that volatile anesthetics are promising agents to prevent neuronal injury during the early ischemic period and provide additional time for the administration of other neuroprotective agents.

\section{References}

1. Wells BA, Keats AS, Cooley DA. Increased tolerance to cerebral ischemia produced by general anesthesia during temporary carotid occlusion. Surgery 1963; 54: 216-23.

2. Park HP, Jeong EJ, Kim MH, Hwang JW, Lim YJ, Min SW, et al. Effects of sevoflurane on neuronal cell damage after severe cerebral ischemia in rat. Korean J Anesthesiol 2011; 61: 327-31.

3. Miura Y, Grocott HP, Bart RD, Pearlstein RD, Dexter F, Warner DS. Differential effects of anesthetic agents on outcome from near-complete but not incomplete global ischemia in the rat. Anesthesiology 1998; 89: 391-400.

Corresponding author: Sungsik Park, M.D., Ph.D., Department of Anesthesiology and Pain Medicine, School of Medicine, Kyungpook National University, Samduk-2 ga, Joong-gu, Daegu 700-721, Korea. Tel: 82-53-420-5863, Fax: 82-53-426-2760, E-mail: sspark@knu.ac.kr

(c) This is an open-access article distributed under the terms of the Creative Commons Attribution Non-Commercial License (http:// creativecommons.org/licenses/by-nc/3.0/), which permits unrestricted non-commercial use, distribution, and reproduction in any medium, provided the original work is properly cited. 
4. Pape M, Engelhard K, Eberspacher E, Hollweck R, Kellermann $\mathrm{K}$, Zintner S, et al. The long-term effect on neuronal cell damage and expression of apoptotic factors after cerebral ischemia and reperfusion in rats. Anesth Analg 2006; 103: 173-9.

5. Engelhard K, Werner C, Eberspacher E, Pape M, Stegemann U, Kellermann K, et al. Influence of propofol on neuronal damage and apoptotic factors after incomplete cerebral ischemia and reperfusion in rats: A long-term observation. Anesthesiology 2004;
101: 912-7.

6. Bayona NA, Gelb AW, Jiang Z, Wilson JX, Urquhart BL, Cechetto DF. Propofol neuroprotection in cerebral ischemia and its effects on low-molecular-weight antioxidants and skilled motor tasks. Anesthesiology 2004; 100: 1151-9.

7. Kawaguchi M, Kimbro JR, Drummond JC, Cole DJ, Kelly PJ, Patel PM. Isoflurane delays but does not prevent cerebral infarction in rats subjected to focal ischemia. Anesthesiology 2000; 92: 1335-42. 